\section{Frei José Mariano da Conceição Veloso e a divulgação de técnicas industriais no Brasil colonial: discussão de alguns conceitos das ciências químicas}

Friar José Mariano da Conceição Veloso and the promotion of industrial techniques in colonial Brazil: discussion of some concepts from the chemical sciences

Fernando J. Luna

Pesquisador e professor do Curso de Pós-Graduação em Ciências Naturais / Universidade Estadual do Norte Fluminense Centro de Ciência e Tecnologia, UENF,

Av. Alberto Lamego, 2000

28013-602 Campos dos Goytacazes - RJ - Brasil fernando@uenf.br

Recebido para publicação em julho de 2007. Aprovado para publicação em maio de 2008.
LUNA, Fernando J. Frei José Mariano da Conceição Veloso e a divulgação de técnicas industriais no Brasil colonial: discussão de alguns conceitos das ciências químicas. História, Ciências, Saúde - Manguinhos, Rio de Janeiro, v.16, n.1, jan.-mar. 2009, p.145-155.

Resumo

Na virada para o século XIX, o botânico mineiro frei Veloso desenvolveu intensa atividade de publicação de livros com intuito de divulgar aos colonos do império português técnicas para o melhoramento da produção agrícola e da incipiente indústria química. Este artigo aborda o primeiro tomo da Alographia dos alkalis fixos..., obra que contém artigos, capítulos de livros, cartas e patentes coligidos de uma dezena de autores, especialmente franceses e ingleses, sobre o conhecimento científico e técnico necessário para produção de carbonato de potássio a partir de cinza de plantas autóctones. Alguns conceitos e definições da época da Revolução Química são discutidos, levando em conta como Veloso os traduziu para o português e os introduziu no Brasil por meio de sua obra.

Palavras-chave: história da tecnologia; Brasil colônia; iluminismo; potassa.

Abstract

At the turn of the 19th century, Minas Gerais Botanist Friar Veloso worked intensely on the publication of books to promote among settlers from the Portuguese empire techniques for improving agricultural production and from the incipient chemistry industry. This article analyzes the first volume of the "Alographia dos alkalis fixos...", a work that includes articles, book chapters, letters and patents from ten authors, particularly French and English, about the scientific and technical knowledge needed for the production of potassium carbonate from the ash of native plants. Some concepts and definitions used at the time of the Chemical Revolution are discussed, considering that Veloso translated them to Portuguese and introduced them to Brazil through his work.

Keywords: history of technology; colonial Brazil; enlightenment; potassa. 
U ma das importantes conseqüências do programa de reformas no império português liderado pelo marquês de Pombal (1699-1782), no final do século XVIII, foi a consolidação das idéias iluministas - e da ciência moderna - trazidas pelos professores contratados no exterior para a Universidade em Coimbra (Wehling, Wehling, 1994, p.152). Do ponto de vista econômico, o período foi caracterizado pelo aumento da demanda por matérias-primas devido à Revolução Industrial que se iniciava, pela necessidade de reagir à crise econômica dos últimos anos do governo de Pombal, pelo declínio da mineração do ouro brasileiro, pela revalorização da política agrícola em Portugal e pela concorrência com os produtos trazidos das colônias européias no Caribe. Segundo Lopes (1997, p.29), foi em tal contexto que a história natural - particularmente a botânica porque estava intimamente ligada à medicina, à agricultura e à química - tornou-se uma preocupação explícita dentro das políticas governamentais em relação às colônias, em particular o Brasil, como explica Maria Odila da Silva Dias (jan.-mar. 1968, p.131):

A política de industrialização de Portugal, encetada por Pombal, gerando um movimento de incentivo da produção de matérias-primas no Brasil; a influência de princípios fisiocratas; a decadência do ouro e a volta para a agricultura, a política de inovações e de reformas determinada no Brasil, sobretudo, pela necessidade de formar os elementos indispensáveis à administração e à vida da nação no Nôvo Mundo desencadeara ... uma série de conseqüências culturais, em que os brasileiros exerceram papel ativo.

O governo português, segundo Ferraz (1997, p.78-91), passou a estimular e promover nas colônias um aumento na quantidade e qualidade dos produtos exportáveis, através de iniciativas como a impressão e circulação de um vasto número de 'memórias' que a Coroa começou a publicar, principalmente a partir de 1770, com o intuito de fomentar a produção de matérias-primas que pudessem auxiliar no processo de industrialização de Portugal e promover um renascimento da agricultura.

Como ministro das Relações Exteriores de Portugal a partir de 1790 e como secretário de Estado interino para os domínios ultramarinos da rainha d. Maria I (1734-1816) a partir de 1795, d. Rodrigo de Souza Coutinho (1755-1812) exerceu papel fundamental na divulgação do Iluminismo no Brasil, ainda que a historiografia hegemônica tenha preferido celebrar o consulado de Pombal, à custa dos períodos imediatamente anterior e posterior este iniciado com a Viradeira, a ascensão de d. Maria ao trono. Diogo Curto (2000, p.11) atribui tal interpretação à historiografia liberal, ao passo que estudos mais recentes têm destacado a continuidade da maioria das orientações e princípios de d. José I (1714-1777), pai e antecessor imediato da Rainha Louca. Assim, a Universidade de Coimbra pôde continuar a formar intelectuais ilustrados e produzir quadros para a alta burocracia mesmo depois da queda de Pombal. Seu sucessor e afilhado d. Rodrigo, uma vez no poder, engajou uma força-tarefa de brasileiros eruditos com o objetivo de elaborar uma política nacional que pudesse garantir a Portugal "a conservação de seus tão vastos domínios particularmente os da América, que fazem propriamente a base da grandeza de nosso augusto trono", citando suas próprias palavras em discurso proferido ao parlamento (citado em Maxwell, 1999, p.187). Entre esses brasileiros eruditos encontravam-se alguns que participaram da conspiração mineira de 1789, o que demonstra uma ousadia política de d. Rodrigo, que Kenneth Maxwell qualifica como "pouco menos que revolucionária" (p.187). Ao empregar 
no governo português os brasileiros que de outra forma abraçariam um indesejado nacionalismo brasileiro, ou até mesmo a causa republicana, d. Rodrigo promoveu o desarme das tensões entre metrópole e colônia e já preparava, com essa 'geração de 1790', o terreno para a bem-sucedida transmigração da corte portuguesa, que não tardaria a acontecer. Resultou que a geração luso-brasileira de 1790, cevada nessas circunstâncias, viria a ser extremamente influente nas décadas seguintes; e foi o próprio d. Rodrigo quem se tornou a figura de proa da primeira monarquia instalada no Rio de Janeiro, em 1808.

Frei José Mariano da Conceição Veloso, um dos principais nomes da ciência e da tecnologia do império português entre o final do Setecentos e o início do século XIX, era primo de Joaquim José da Silva Xavier (1746-1792) e foi objeto de um ensaio biográfico extremamente elogioso em 1858, escrito pelo vice-presidente do Instituto Histórico e Geográfico Brasileiro. Neste se aprende que, de nome secular "José Veloso Xavier, viu a luz e foi baptizado na Freguezia de Sancto Antonio da Villa de S. José1, comarca do Rio das Mortes, Bispado de Marianna, no anno de 1742" (Lagos, 1858, p.597), tendo-se tornado religioso ao mesmo tempo em que se dedicava aos estudos das plantas: "pesquisava seus nomes, com attenção notava suas differenças, e mesmo muitas vezes deixou de ir á aula afim de se entranhar nos bosques a procurar flores, e estudar a natureza..." (p.598). Em 1790 mudou-se para Lisboa (Blake, 1899, p.64), onde desenvolveu trabalhos de classificação de espécies naturais trabalhando no Real Museu e Jardim da Ajuda e na Academia Real das Ciências de Lisboa, enquanto preparava a publicação de Florae fluminensis, sua obra científica mais significativa. Veloso descreveu quatrocentas novas espécies de plantas pertencentes à flora brasileira e foi o criador de 66 gêneros de plantas (Azevedo, 1964, p.255). No entanto, depois de enfrentar 'desinteligências' com membros da Academia, foi desligado da instituição e regressou ao Brasil, após a fuga da família real causada pelas invasões francesas, passando a morar no Rio de Janeiro. Frei Veloso morreu em julho de 1811, depois de passar os três últimos anos de vida enclausurado no convento de Santo Antônio, no centro da cidade do Rio de Janeiro, em cujo claustro foi enterrado.

Neste artigo detenho-me em alguns conceitos e definições das ciências químicas do final do século XVIII, ou seja, durante o período de nascimento da química moderna, na forma em que foram traduzidos para a língua portuguesa por Veloso e introduzidos no Brasil na esteira do projeto iluminista do império português que estava em implementação. A principal contribuição de Veloso para a indústria da América portuguesa foi a divulgação de publicações sobre técnicas industriais, com destaque para as atividades que poderiam ser desenvolvidas no Brasil. A atividade editorial e de tradutor de artigos científicos sobre os mais diversos temas, a que se dedicou diligentemente em Lisboa, permite ilustrar a extensa capacidade transdisciplinar de frei Veloso. O longo rol de obras publicadas na Tipografia Calcográfica e Literária do Arco do Cego (entre 1799 e 1801) ou pela sucedânea Imprensa Régia, instituições dirigidas por ele mesmo, incluía temas como mineração e instalação de fábricas, além de agricultura e criação de animais e até mesmo manuais de desenho e pintura (Nunes, Brigola, 1999, p.69). Ao entregar a direção da recém-criada Tipografia do Arco do Cego a Veloso, d. Rodrigo colocava em prática seu projeto político, que consistia em realçar a importância do Brasil para o vigor do Império. A produção de livros sobre o Brasil se tornara fundamental no mesmo momento em que falhava a 
prosperidade comercial da metrópole. De forma análoga à missão da Academia Real, o objetivo era levar as idéias fisiocráticas às colônias e difundir as luzes das ciências, sobretudo os saberes ligados à agricultura (Curto, 1999, p.48).

Enquanto trabalhava em Lisboa, Veloso desenvolveu profícua atividade de contatos e entendimentos com diversos impressores, tendo por objetivo publicar livros que pudessem instrumentalizar a incipiente indústria, a agricultura e a história natural. Pretendia divulgar informações úteis para o melhor conhecimento e exploração de culturas agrárias como a cana-de-açúcar, o tabaco, o chá, o café, o cacau, o arroz, a batata, as plantas tintoriais, por exemplo. Sua obra de maior fôlego na área da tecnologia, constituída em dez volumes e impressa em Lisboa entre 1798 e 1806, foi denominada O fazendeiro do Brasil, cultivador, melhorado na economia rural dos gêneros já cultivados e de outros, que se podem introduzir e nas fábricas, que lhe são próprias, segundo o melhor, que se tem escrito a este assumpto (Wegner, 2004, p.131).

Já no livro denominado Alographia dos alkalis vegetal ou potassa, mineral ou soda e dos seus nitratos ${ }^{2}$, Veloso reuniu artigos e outras publicações dos centros mais avançados da época, especialmente França e Inglaterra, e os traduziu para o português por encomenda do príncipe regente. Em um único volume, com mais de trezentas páginas, reuniu traduções de artigos, folhetos, comunicações, cartas, privilégios ${ }^{3}$ e capítulos de livros escritos por mais de uma dezena de autores europeus para tratar do conhecimento científico e tecnológico necessário à fabricação do carbonato de potássio, conhecido como potassa. A intenção era disponibilizar um manual completo, suficiente para explicar aos leitores brasileiros as operações básicas para o aprimoramento das atividades da incipiente produção industrial no Brasil colonial, de acordo com as técnicas estabelecidas na Europa (Vita, Teixeira, Luna, set.-out. 2007, p.1.386).

A soda e a potassa eram consideradas 'álcalis fixos' diferentes; além destes, no final do século XVIII eram conhecidos outros quatro tipos de álcalis: barita, estroncita, a cal e o amoníaco. Industrialmente destacavam-se a soda (álcali fixo mineral), a potassa (álcali fixo vegetal) e o amoníaco. As demais eram tão-somente terras alcalinas que tinham a propriedade de formar sabão ao serem misturadas com gorduras ou óleos. A soda e a potassa eram chamadas álcalis fixos porque resistem à ação do fogo; por outro lado o amoníaco (hidróxido de amônio) era definido como álcali volátil porque evapora ao ser submetido ao calor.

Até a metade do século XIX tanto a potassa quanto a soda eram produzidas principalmente pela queima de certos tipos de plantas. A Espanha, talvez desde a época da permanência árabe, foi um importante produtor, especialmente de soda. Lembremo-nos de que a soda de Alicante era a mais indicada para obtenção de vidros e cristais finos, de lentes para instrumentos ópticos e para os melhores sabões sólidos e alvos, e de que a lixiviação de cinzas da madeira e de plantas terrestres foi a principal forma de produção até o início da exploração dos depósitos minerais de cloreto de potássio na Alemanha, em 1861 (Carrara Jr., Meirelles, 1996, p.31). O advento do processo Leblanc, de produção industrial de carbonato de potássio, fez desaparecer completamente a produção de álcalis pela queima de plantas, e os instrumentos utilizados para produção da potassa ou da soda também desapareceram, sendo escassos os relatos sobre o assunto (Pérez, Tascón, 1990, p.214). 
Frei Veloso explica, ao final do primeiro volume da Alographia dos alkalis... (Veloso, 1798, p.246), que sua obra sobre o estudo dos álcalis era composta de três tomos: "I. Tom. Potassa, na Officina de Simão Thaddeo, 1798; II. Tom. Soda, na dita Officina, 1798; III. Tom. Salitre, na Officina Patriarchal de João Procopio Correa da Silva, 1798". Somente o primeiro tomo foi localizado na Seção de Obras Gerais da Biblioteca Nacional no Rio de Janeiro. No prefácio desse volume, dirigindo-se ao príncipe regente d. João (1767-1826), Veloso (1798, p.V) explica que o livro "trata da natureza, e do methodo de se fazer, ou extrahir o Alkali fixo vegetal, conhecido pelo nome de potassa, segundo os Authores dos quaes se trasladarão [ou seja, traduzirão] os papéis inscritos nesta collecção". O prefácio também esclarece que a tradução foi encomendada pelo príncipe e consumiu três meses de trabalho. No volume encontramos figuras detalhando planos para a construção de fábricas de potassa que, uma vez em funcionamento, proporcionariam significativa economia de divisas para Portugal, ou ainda, nas palavras de Veloso, "pouparão muito numerário" gasto com a importação de potassa do "norte da Europa, e da América, Índia e Hespanha", sendo beneficiadas diretamente as nossas "saboarias, vidrarias, tinturarias, branquearias, a agricultura, a química, a farmácia, etc." (p.VII).

É de Richard Watson o artigo "Of saline substances", escolhido por Veloso para abrir a Alographia. Searby, Leader e Morgan (2004, p.218) relatam que, apesar de ser "ignorant of chemistry", Richard Watson (1737-1816) tornou-se professor de química na Universidade Cambridge aos 27 anos, tendo sido então obrigado a passar um ano e dois meses no laboratório preparando-se para o cargo. Em 1771 foi apontado professor régio de teologia, como indica Veloso na página de rosto da seção que incluiu na Alographia, mas, tendo continuado a publicar trabalhos sobre química, acabou ficando mais conhecido como químico do que como religioso.

Watson inicia o ensaio com uma curta digressão sobre os limites das teorias de que dispunha no século XVIII para definir seu objeto de estudo, que Veloso $(1798$, p.1) traduz assim:

Quererião alguns que esta Memoria principiasse, dando huma rigorosa definição da palavra Sal, ou substância salina, como se as idéas, que concebemos, das substancias naturaes se podessem sujeitar a estas definições rigorosas ou descripções exactas, ou que a Natureza, procedendo por gradações insensíveis, tivesse sido tão liberal, que nos houvesse deixado algumas notas decisivas, pelas quaes podéssemos invariavelmente distinguir o seu genero intrinseco.

É interessante notar que no mesmo volume em que se fornecem descrições eminentemente práticas sobre a produção de um insumo industrial são elaboradas discussões sobre fundamentos da ciência química e, até mesmo, considerações sobre o que hoje classificaríamos como filosofia da ciência, como o trecho acima. O autor inglês passa então a discutir o que pode e o que não pode ser classificado como sal e explica que duas características atribuíveis aos sais são "1o. ter sabor; 2o. ser solúvel em água" (Veloso, 1798, p.1) e que, a estas, alguns estudiosos teriam acrescentado a propriedade de ser incombustível. Conclui "que toda a substancia, que for soluvel em agua, [e] é capaz de afectar pelo seu sabor o orgão, pode com toda segurança ser chamada Sal" (p.2). Em seguida, contrapõe o exemplo do cobre, que "mastigado por algum tempo, excita hum gosto nauseoso, e por 
huma longa persistência n'agua se dissolve em parte, e a pezar disto se não tem posto o cobre na classe dos Saes, ou das substancias salinas" (p.2). Watson continua afirmando que se a classificação fosse feita chamando de sal todo corpo que tenha figura regular, teriam que ser incluídos pedras preciosas, vidros e substâncias metálicas, que são insípidas e não têm solubilidade em água. Até mesmo a água, argumenta Watson, quando em forma de gelo, não poderia ser considerada um sal, apesar de ter forma definida. O autor contenta-se, portanto, em restringir sua definição a duas características, o sabor e a solubilidade n'água, e acrescenta que todos os sais podem ser reduzidos a uma das três 'espécies' seguintes: sal ácido, sal alcalino e sal neutro. O sabor é a característica mais relevante para se fazer a diferença entre os três tipos de sal, sendo que o primeiro, além de ter sabor ácido como "as azedas, o vinagre, o cremor de tártaro, os limões, os tamarindos" (p.3), tem a propriedade de mudar a cor de azul para vermelho de plantas como a violeta (Viola odorata L.).

A seção seguinte do livro de frei Veloso, também traduzida do trabalho de Watson, trata "dos alkalis" e inicia com uma explanação etimológica da palavra, que tem origem na fusão do prefixo árabe al com o nome de uma planta, kali (Veloso, 1798, p.4). Nesse ponto, como era comum entre os tradutores da época, Veloso permite-se adicionar uma nota de rodapé ao artigo que está traduzindo para explicar que álcali fixo é o mesmo que potassa, palavra emprestada do inglês pot ash, ou seja "cinza de panella, fogão, lenhas" (p.4), e que álcali fixo mineral pode ser chamado de soda, por causa do francês soude, mas que na Espanha, por sua vez, recebe duas denominações distintas, barrilla, quando é mais pura, e soza, quando tem maior grau de impurezas.

A segunda parte da Alographia... é um excerto do livro Catálogo methodico e explicado da collecção dos fossis ou cavadiços pertencentes a illustrissima Leonor de Raab, escrito por Ignaz von Born (1742-1791), mineralogista austríaco e professor na Universidade de Praga, que foi chamado para organizar o Naturaliencabinet ${ }^{4}$ da imperatriz Maria Teresa e ser o tutor das princesas. Von Born tornou-se rico e famoso ao desenvolver uma técnica para amalgamar ouro e prata e foi o organizador do que pode ser considerado o primeiro congresso científico internacional, em 1784 (Drace-Francis, Jan. 2006, p.61). Aqui, novamente, há uma discussão sobre a definição do que pode ser considerado um sal, de acordo com os conceitos de química disponíveis no final do século XVIII. Em seguida são apresentadas algumas propriedades dos ácidos muriático ${ }^{5}$, nítrico, fluórico e sulfúrico, em que se menciona "Mr. Lavoisier, um dos Chymicos mais exactos, mais illuminados, e mais celebres deste seculo" e que estabeleceu que o ácido sulfúrico, conhecido então como ácido vitriólico, era tão somente um composto de enxofre e "ar vital, ou princípio oxygeno" (Veloso, 1798, p.19). Quando se refere ao sal amoníaco ${ }^{6}$ inclui uma explicação sobre a origem do termo amoníaco, atribuindo aos antigos que "o tiravão o paiz da Lybia, onde esteve situado o templo de Jupiter Ammon" (p.46). Finalmente, ao tratar do 'carbonato de potassa', esclarece que, até a descoberta de Lavoisier, não se fazia distinção entre o sal carbonato de potássio e o álcali puro (o hidróxido de potássio), mas "depois da descoberta do Gaz se sabe que somente he um sal neutro imperfeito, que resulta da combinação do Alkali vegetal, ou potassa com o ácido aereo [palavra ilegível], ou carbonico" (p.54).

Em 1798, Jean Antoine Chaptal (1756-1832) ainda não havia escrito seu Chimie appliquée aux arts, um dos primeiros livros de química industrial do Ocidente; portanto, Veloso teve 
de se contentar em traduzir a seção VIII dos Élemens de chimie, obra publicada por Chaptal entre 1790 e 1803. Inicialmente Chaptal havia estudado medicina, mas se tornou químico, além de ter sido ministro do Interior da França e fundado as primeiras fábricas de produtos químicos naquele país (Rey, 1994, p.423). Assim como no texto traduzido de Watson, Chaptal discute, a princípio, as propriedades que bastam para caracterizar os álcalis, e arrola o sabor, a capacidade de mudar a cor dos indicadores acidobásicos, a "virtude de formar o vidro, sendo fundido com substâncias quartzosas" e de reagir ${ }^{7}$ com ácidos para formar sais, além de a "faculdade de fazer os óleos se misturar com a água". Dadas as definições, o químico francês enumera sete regras de como escolher as melhores plantas para a produção da soda e da potassa por combustão. De acordo com Chaptal, lido a partir da tradução de Veloso, a combustão pode ser feita em fornos ordinários, em lareiras, em fogões ou a céu aberto, desde que não haja ventania. Para extração do salino contido nas cinzas é preciso lavá-las com água, ou seja, lixiviá-las e, em seguida, reduzir o volume da solução obtida por evaporação até a secura (Veloso, 1798, p.91).

A seção final da Alographia..., denominada Flora Alográfica, não é mais uma tradução e sim um estudo de autoria do próprio Veloso, que apresenta estampas e descrições botânicas de 22 plantas brasileiras que podiam servir para a produção de potassa pela queima, entre as quais se encontram a bananeira, o girassol e o milho. É de notar que, aqui, o autor da Florae fluminensis, que viria a contar com 1.700 estampas originais de plantas do Rio de Janeiro (Ferri, 1994, p.182), pede perdão pela má qualidade das estampas reproduzidas de outras fontes.

Robert Wegner (2004, p.131) aponta evidências sobre a efetiva disseminação, no Brasil, dos conhecimentos e das informações tecnológicas contidas nas obras de Veloso. Afinal de contas, o objetivo explícito do frade era educar os colonos para que aumentassem a produtividade de suas atividades econômicas, o que somente seria realizado se os livros não só chegassem ao Brasil mas também fossem lidos e, dessa leitura, resultasse a melhoria da produção local. Uma das evidências citadas encontra-se nos agradecimentos devotados ao rei pelo próprio Veloso, em tradução de uma obra sobre a cana-de-açúcar, em que afirma que "os fabricantes de açúcar têm melhorado as sua moendas e fornalhas" (Veloso, 1801 , s.p.). Veloso também menciona que teria "recebido cartas de agradecimento de pessoas ... desconhecidas".

Segundo grande parte da historiografia oficial das ciências no Brasil, não existiram atividades científicas no país durante todo o período colonial. De fato, até cerca de vinte anos atrás a atividade desenvolvida no país antes de 1900 foi praticamente ignorada. No entanto já se consolida uma historiografia da ciência que se contrapõe àquela praticada por quase todo o século XX, que categorizava como 'pré-científico' o período colonial brasileiro. A leitura cuidadosa da Alographia... de Veloso, escrita em 1798, fornece argumentos para combater o julgamento dos que negam a existência da prática científica no período colonial. As atividades científicas que o frade praticou no Brasil e em Portugal podem ser consideradas um exemplo perfeito da fase dois, ou 'ciência colonial', conforme o modelo de Basalla (May 1967), para quem o cientista pode ser um "native or a transplanted European colonist or settler, but ... the sources of his education, and his institutional attachments, are beyond the boundaries of the land in which he carries out his scientific work" (p.611). 


\section{$5-3+1$ \\ A L O G R A P I A \\ DOSALKALIS FIXOS}

VEGETAL OU POTASSA, MINERAL OU SODA B DOS SEUS Nitratos,

$$
\text { S E G U N D O }
$$

AS MELHORES MEMORIAS ESTRANGEIRAS,

Que se tem escripto a este assumpro.

DEBAIXO DOS A USPICIOS

E D E OR D E M

\section{$\mathrm{D} z$ \\ SUA A L TEZZA R E A L \\ PRINCIPE DO BRAZIL. \\ NOS S S E N HOR. \\ P 2}

Fi. JOSE MARIANNO DA CONCEIÇĂO VELLOSO,

Menor Reformado da Provinsia da Conccigäo do $\boldsymbol{R}$ io de Janciro, Es.

PARTE PRIMEIRA Do Alkali fixo vegetal ou Pctassa

Ignari discens, ament montinisse periti

Hosat.

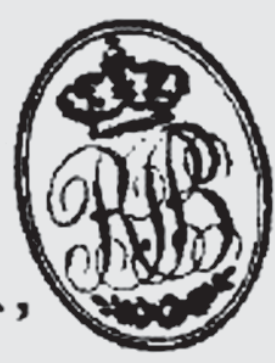


Não somente havia ciência relevante no Brasil setecentista, mas vimos também que um nativo de Minas Gerais, mesmo não tendo estudado em Coimbra, teve significativa atividade científica, marcada por rigoroso caráter utilitário e voltada para o avanço da tecnologia, prática remanescente nos dias atuais, em que as agências governamentais pregam a necessidade da transformação da pesquisa realizada nas universidades em produtos com valor de mercado.

A preocupação com a utilidade prática é uma questão central para as ciências durante o iluminismo francês. Lavoisier, por exemplo, aliou suas atividades de reformador da química a ocupações mais mundanas, como a análise das águas consumidas em Paris, a conservação

\section{FLORA ALOGRAPHICA}

$\mathrm{D} \boldsymbol{A} \mathbf{s}$

HERVAS CONTHEUDAS NESTA OBRA,

B D EOUTKAS

D 0

B R A Z I L,

Cuja incineraçăo póde dar huma maior abundancia do Alkali

fixo Vegetal, ou Potassa :

ENRIQUECIDA COMESTAMPAS:

DEB AIXO DOS AUSPIGIOS

E DEOR D E M

$\mathbf{s}$

S U A A L T E Z A REA L

$\circ$

PRINCIPE DO BRAZIL

NOS O S E N H O R.

P 0 R

fr. JOSÉ MARIANNO DA CONCEIÇĂO VELLOSO.

Ignari discam, ament menninisse periti

Horat. 
dos alimentos e a agricultura (Kury, 2001, p.127). A rigor, como explica Schneiders (2006, p.35), o Século das Luzes começou com Voltaire, principal defensor do empirismo e das idéias de Newton, que promoveu a identificação do iluminismo francês com o modo de pensar forjado pelas ciências empíricas, até que o suíço Rousseau viesse demolir a idéia de que a filosofia natural, as ciências e a mecânica poderiam transformar e melhorar o mundo por meio de inventos e descobertas úteis ao bem-estar da humanidade. Segundo Maria Odila S. Dias (jan.-mar. 1968, p.106-108), esse 'antiintelectualismo' de Rousseau não teve maior repercussão entre eruditos brasileiros, assim como também não os entusiasmaram suas idéias democráticas, evidentemente em virtude de seus privilégios de aristocratas. Por outro lado, as idéias de Voltaire e dos enciclopedistas franceses tiveram grande influência sobre a elite científica de Portugal e seus domínios coloniais no fim do século XVIII, como demonstram os numerosos trabalhos de ciência aplicada a que se dedicaram brasileiros como o próprio frei Veloso, Alexandre Rodrigues Ferreira e José Bonifácio de Andrada e Silva, entre muitos outros.

A fidelidade das traduções dos trabalhos de Watson (1781, p.109-148) e Born, (De Born, 1790, s.p.) encontradas na Alographia..., pôde ser constatada compulsando-se os originais e pelo acompanhamento do diálogo que Veloso estabeleceu com esses autores por meio de notas de rodapé. Além das boas traduções, a leitura desses textos revela o polímata que transitava com autoridade entre a botânica, as ciências químicas e a química industrial, tornando ao menos instigante o lamento encontrado no prefácio de outra tradução, que Veloso publicou no ano seguinte ao da Alographia...: " [a] certeza, que tenho (não sei se justa) de naõ termos ainda hum só escrito nosso, ácerca da Historia Natural desse Reino, e ainda de suas Colonias, naõ por falta de pessoas de talentos" (Veloso, 1799, s.p.).

\section{AGRADECIMENTOS}

À Faperj (projeto número E-26/110.532/2007 ) e Otávio Rios, da Universidade do Estado do Amazonas, pela leitura cuidadosa e por valiosas sugestões.

\section{NOTAS}

${ }^{1}$ Atual cidade de Tiradentes (MG).

2 Veloso (1798, p.7) esclarece, no "Aviso ao leitor", que deu "nome de Alographia por tratar da natureza dos sais". O prefixo 'alo-' deve-se referir então aos halogênios presentes em alguns tipos de sais.

${ }^{3}$ Ou seja, patentes.

${ }^{4}$ Cuja coleção foi mais tarde incorporada ao Museu de História Natural, Naturhistorichesmuseum, de Viena.

${ }^{5}$ Nosso ácido clorídrico.

${ }^{6}$ Nosso cloreto de amônio.

7 Veloso escreve "ferver".

\section{REFERÊNCIAS}

AZEVEDO, Fernando de.

A cultura brasileira. 4.ed.

São Paulo: Melhoramentos. 1964.
BASALLA, George.

The spread of western science. Science,

Washington, v.156, n.3.775, p.611-622. May 1967. 
BLAKE, Augusto Victorino Alves Sacramento. Diccionario bibliographico brazileiro. v.5. Rio de Janeiro: Typographia Nacional. 1899.

CARRARA JR., Ernesto; MEIRELLES, Helio. A indústria química e o desenvolvimento do Brasil. t.1. São Paulo: Metalivros. 1996.

CURTO, Diogo Ramada.

Introdução. In: Domingos, Manuela D. Livreiros de Setecentos. Lisboa: Biblioteca Nacional. p.11-16. 2000.

CURTO, Diogo Ramada.

D. Rodrigo de Souza Coutinho e a Casa Literária do Arco do Cego. In: Campos, Fernanda Maria Guedes de et al. (Org). A Casa Literária do Arco do Cego (1799-1801) bicentenário: "sem livros não há instrução". Lisboa: Imprensa Nacional; Casa da Moeda; Biblioteca Nacional. p.15-49. 1999.

DE BORN, Ignaz.

Catalogue methodique et raisonné de la collection des fossiles de Mlle. Éléonore de Raab. t.1. Viena: Aux Dépens de J. V. Degen, par I. Alberti. 1790.

DIAS, Maria Odila da Silva.

Aspectos da Ilustração no Brasil. Revista do Instituto Histórico e Geográfico Brasileiro,

Rio de Janeiro, v.278, p.105-170. jan.-mar. 1968.

DRACE-FRANCIS, Alex.

A provincial imperialist and a 'Curious account of Wallachia': Ignaz von Born. European History Quarterly, London, v.36, n.1. p.61-89. Jan. 2006.

FERRAZ, Maria Helena Mendes.

As ciências em Portugal e no Brasil, 1772-1822:

o texto conflituoso da química.

São Paulo: Educ. 1997.

FERRI, Mário Guimarães.

A botânica no Brasil. In: Azevedo, Fernando de (Org). As ciências no Brasil. v.2. 2.ed.

Rio de Janeiro: Editora UFRJ. p.175-231. 1994.

KURY, Lorelai.

Entre utopia e pragmatismo: a história natural no Iluminismo tardio. In: Soares, Luiz Carlos (Org). Da revolução científica à big (business) science. São Paulo: Hucitec. p.105-153. 2001.

LAGOS, Manuel Ferreira.

Elogio histórico do padre mestre fr. José Marianno da Conceição Veloso. Revista do Instituto Histórico e Geográfico Brasileiro, Rio de Janeiro, t.2, p.596-614. 1858.

LOPES, Maria Margaret.

O Brasil descobre a pesquisa científica: os museus e as ciências naturais no século XIX. São Paulo: Hucitec. 1997.

MAXWELL, Kenneth.

Chocolate, piratas e outros malandros: ensaios tropicais. Rio de Janeiro: Paz e Terra. 1999.

NUNES, Maria de Fátima; BRIGOLA, João C. José Mariano da Conceição Veloso (1742-1811)
- um frade no universo da natureza. In: Campos, Fernanda Maria Guedes de et al. (Org). A Casa Literária do Arco do Cego (17991801) - bicentenário: "sem livros não há instrução". Lisboa: Imprensa Nacional; Casa da Moeda; Biblioteca Nacional. p.51-75. 1999.

PÉREZ, Joaquim Fernandez; TASCÓN, Ignacio Gonzalez.

La agricultura viajera, cultivos y manufacturas de plantas industriales y alimentarias en España y em la América Virreinal. Madrid: Consejo Superior de Investigaciones Científicas. 1990.

REY, Alain (Org.).

Le Petit Robert des noms propres.

Paris: Dictionnaires le Robert. 1994.

SCHNEIDERS, Werner.

Concepts of philosophy. In: Haakonssen, Knud (Org.) The Cambridge history of eighteenthcentury philosophy. v.1. Cambridge: University Press. 2006.

SEARBY, Peter; LEADER, Damian R.; MORGAN, Victor.

A history of the University of Cambridge. v.3

(1750-1870). Cambridge: University Press. 2004.

VELOSO, José Mariano da Conceição.

Compendio sobre a canna, e sobre os meios de se lhe extrahir o sal essencial, ao qual se ajuntaõ muitas memorias ao mesmo respeito, dedicado á colonia de S. Domingos. Lisboa: Typographia Chalcographica, Typoplastica, e Litteraria do Arco do Cego. 1801.

VELOSO, José Mariano da Conceição. Helminthologia portugueza. Lisboa: Officina de Joaõ Procopio Correa da Silva. 1799.

VELOSO, José Mariano da Conceição. Alographia dos alkalis fixos vegetal ou potassa, mineral ou soda e dos seus nitratos, segundo as melhores memorias estrangeiras, que se tem escripto a este assumpto parte primeira. Lisboa: Offic. de Simão Thaddeo Ferreira. 1798.

VITA, Soraya; TEIXEIRA, Simonne; LUNA, Fernando J.

Descrições de técnicas da química na produção de bens de acordo com os relatos dos naturalistas viajantes no Brasil colonial e imperial. Química Nova, São Paulo, v.30, n.5, p.1.381-1.386. set.-out. 2007.

WATSON, Richard.

Chemical essays. v.1. London: T. and J. Evans. 1781.

WEGNER, Robert.

Livros do Arco do Cego no Brasil Colonial. História, Ciências, Saúde - Manguinhos, Rio de Janeiro, v.11, supl. 1, p.131-140. 2004.

WEHLING, Arno; WEHLING, Maria José C. de M. Formação do Brasil colonial. Rio de Janeiro: Nova Fronteira. 1994. 